\author{
Military Technical College \\ Kobry El-Kobbah, \\ Cairo, Egypt.
}

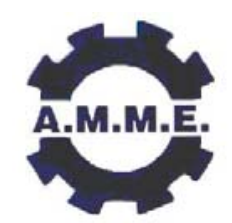

$13^{\text {th }}$ International Conference on Applied Mechanics and Mechanical Engineering.

\title{
MODELLING OF LIGHT RANGE COMMERCIAL VEHICLE PROPELLER SHAFTS UNDER DYNAMIC EFFECTS
}

\author{
TAYMAZ* I., CAKIR* K., GUNEY* B., GUNDOGAR* E. and CETINER ${ }^{* *}$ I.
}

\begin{abstract}
Propeller shafts are the main components of a vehicle that transmit power from gearbox flange to differential flange enabling the wheels of the vehicle to rotate. Depending upon the vehicle geometry and dimensions the vehicle might have one or more propeller shafts at a time. In case of two or more shaft usage, most of the time the shaft connected to gearbox flange has no length compensation while the latter one does.

In this study front and rear propeller shafts of a selected vehicle have been analysed as finite element models under the effects of torque transmitted from gearbox. Various levels of torque values have been considered and stress analysis have been made. Additionally the angle between shaft axes has been altered to find Von-Mises stress levels. Finally fatigue criteria have been used to find fatigue life expectancy of shafts.
\end{abstract}

\section{KEY WORDS}

Propeller shaft, Torque, Stress analysis, Fatigue

\section{Nomenclature}

C : Section Radius

G : Drive Axle Load

J : Polar Moment of Inertia

$\mathrm{n} \quad$ : Factor of Safety

$\mathrm{T}$ : Torque
$\mathrm{S}_{e} \quad$ : Endurance Limit

$\mathrm{S}_{u t} \quad$ : Ultimate Tensile Strength

$\sigma_{a} \quad$ : Alternating Stress

$\sigma_{m} \quad$ : Mean Stress

$\mu \quad$ : Friction Coefficient 


\section{INTRODUCTION}

Propeller shafts are generally subjected to torque variations that result in shear stresses and stress variations. Under the effect of varying stress levels there might be yielding due to high stress values that are over the yield stress of the material.

Even if yielding might not occur there might be fatigue failure since fatigue behaviour is observed under varying stress levels. Thus a profound stress analysis and fatigue calculations of shafts have been carried out. As a first step the highest torque that can be applied to propeller shafts has been considered.

Since vehicle engine produces $490 \mathrm{Nm}$ maximum torque at $2100 \mathrm{rpm}$ and also the slowest gear ratio of gearbox is 6.00 , then maximum torque transmitted to shafts is $490 \mathrm{Nm}$. $(6.00)=2940 \mathrm{Nm}$. Same procedure has been carried with other six forward gear ratios and one reverse gear ratio. Various analysis have been carried out in finite element environment by changing torque values as well as relative angle between propeller shaft axles. The angle variations have been observed in CAD environment by taking into account of the movement of rear axle. Fig. 1. shows a sketch drawing of the idea of angle variations. Due to angle variations of the propeller shaft axes with respect to gearbox, the application of a sliding joint is inevitable. Also angular velocity variation of rear propeller shaft due to universal joints have been considered. Results could be evaluated easily on graphs illustrated.

Taking into account that shaft tubes' material is St 52 and remaining parts' material is Ck 45 fatigue calculations have been made. The idea is simple enough to find maximum stress values on materials and applying fatigue criteria. In most cases carefully conducted experiments have been made on fatigue subject. For example Farfan et al. [1] carried out high and low cycle fatigue tests regarding fatigue failure. However in real cases some of fatigue variables should be modified as done in this study.

\section{ANALYSIS PROCEDURE}

Stress analysis for propeller shafts under the effect of seven different torque values have been made. These values are 2940Nm, $1671 \mathrm{Nm}, 1063 \mathrm{Nm}, 666 \mathrm{Nm}, 490 \mathrm{Nm}$, $382,2 \mathrm{Nm}, 2675,4 \mathrm{Nm}$. Fig. 2. shows 3D model of shafts and demonstrates constraints applied on the shafts. In this case the applied torque is $2940 \mathrm{Nm}$. The following procedures are exactly same only the applied torque value is changed. In Fig. 2. the angle between shaft axes is $2.16^{\circ}$. In $3 \mathrm{D}$ environment this angle is found to be minimum $2.16^{\circ}$ and maximum $6^{\circ}$. Also the stress values under variable shaft angle have been found and shown on graph. In case of torsional deformations that lead to fatigue behaviour McClaflin et al. [2] should be checked who give out suggestions on life determination.

A sample analysis result is shown in Fig. 3. The results indicate that under the highest torque that can be applied-in this case $2940 \mathrm{Nm}$ - the highest Von-Mises stress value is 386.922 MPa. The value is found to be under yield strength of the material -Ck 45- in the section. The yield strength of $\mathrm{Ck} 45$ is $490 \mathrm{MPa}$. Thus it leads to a safety factor of minimum 1.27. Considering the Von-Mises yield criteria that states the yield strength of 
material as $\sigma_{y}$ and equivalent Von-Mises stress as $\sigma_{v}$, then in order for the material not to yield the criteria $\sigma_{y} \geq \sigma_{v}$ must be satisfied. In this case it is exactly what is required. A close view of the critical section of shafts is presented in Fig. 4. to give a better idea of where yielding first may occur.

A detailed examination of the critical section reveals that high stresses occur at sections where material diameter is considerably small with respect to other cross sections. This is an expected result since Von-Mises stress is

$$
\sigma_{v}=\sqrt{3} \cdot T \cdot(c / J)
$$

where $\mathrm{c}$ is section radius and $\mathrm{J}$ is polar moment of inertia as

$\mathrm{J}=(1 / 2) \cdot \pi \cdot c^{4}$

This means that with decreasing radius stress value increases. The results of stress values are tabulated in Table 1. It is to be noted that as gear ratios decrease - as well as gear numbers increase - stress levels decrease. This is due to reduced torque transmission. In this case rotational speed of shafts increase. Bhaumik et al. [3] used the same formulation while trying to find fatigue failure of hollow power transmission shaft.

The situation is especially risky when first gear or reverse gear is used in vehicles. For the worst case scenario the stress level in first gear will be considered especially when calculating fatigue life of propeller shafts. Under operating conditions the safety factors seem to be ranging from 1.27 to 9.76 . Not in any condition propeller shafts exhibit VonMises yielding.

It is to be noted that these analysis have been made considering that the angle between shaft axes is $2.16^{\circ}$. However as angle is increased the stress values might differ. In these cases the applied torque values should differ that is because the angle between propeller shafts depends on vehicle load. As long as the vehicle load decreases axle springs encounter less load force. As load decreases the axle springs tend to take their $U$ shaped form which increases displacement of axle relative to vehicle chassis. Since axle is directly connected to vehicle spring the axle tend to move away from chassis and also the rear propeller shaft is directly connected to axle differential. As axle moves away from chassis the relative motion increases the angle between propeller shafts. In this case since load is decreased the applied torque decreases.

Applied torque value depends directly on the load exerted on the driving axle. Applied torque value is found from the formulation

$T=(G \cdot 9.81 \cdot r \cdot \mu) / i_{d i f f}$

In this case Bayrakceken [4] explained $i_{\text {diff }}$ as the final gear reduction in the differential case of the axle which increases torque applied to wheels but in turn it reduces rotational speed of tyres. In this formula (3) $G$ represents load applied from driving axle 
tyres to the road which is simply the resultant force at the rear tyres and $\mu$ stands for friction coefficient usually ranging from 0.6 in ordinary road conditions and 1 in the case of off-road vehicles.

In this research Turkish road conditions have been considered and friction coefficient between tyres and road is taken as 0.7 . In the case of off-road conditions or $4 \times 4$ applications the friction coefficient is taken as 1 .

\section{Variable Angle Stress Analysis}

The angle variation between shaft axes has also been evaluated. As this angle increases the usage of simple shear stress formulation could not be used. In the former case where angle is found to be $2.16^{\circ}$ both shafts assumed to be parallel and on one axis. An incremental procedure has been used in this case and analysis has been made from $2.16^{\circ}$ to $6^{\circ}$ by 1 degree increments. The analysis procedure involves varying angle but keeps torque applied steady. Torque values have been taken as the former values mentioned above.

Figure 5 shows the idea of angle variation. Here the angle between shaft axes is denoted as $\beta$. A sample analysis result is shown in Fig. 6 . Here $\beta$ is taken as $6^{\circ}$ and torque applied is $1671 \mathrm{Nm}$. In this case the maximum Von-Mises stress is found to be 313.6 MPa. All around results are tabulated in Fig. 7 to give a better understanding on stress variation vs. angle variation.

Figure 7 gives an idea of what it would be like if propeller shafts encounter different levels of torque under different operating angles. The results reveal that under constant torque stress levels increase. The results tend to increase within increasing torque value. Maximum Von Mises stress value is $475 \mathrm{MPa}$ which occurs at $6^{\circ}$ with $2940 \mathrm{Nm}$ torque. Considering the results presented above, there occurs no yielding due to Von Mises criteria.

\section{FATIGUE LIFE DETERMINATION}

Fatigue life of materials are considered to be found from uni-axial loading to multiaxial loading as well as environmental conditions are considered. For example Sonsino et al. [5] investigated fatigue strength of structural steel St 35 under multiaxial loading. In the same manner Bertini et al. [6] investigated weld treatments' influence on welded joints. Also for low cycle fatigue life of shafts connections - especially contact fatigue - is a problem dealt by Jen [7] et al. and can be inspected under fatigue approaches. Stress concentration factors should also be calculated as a design criteria by applying to Noda et al.[8] for a broader view.

In this paper however the shafts encounter only torsional movement and the effect of torque will be considered. For the worst case scenario the highest stress value found-in this case $386.9 \mathrm{MPa}$ - will be used. The critical section is on material $\mathrm{Ck} 45$. Considering modified Goodman criteria 
$\frac{\sigma_{a}}{S_{e}}+\frac{\sigma_{m}}{S_{u t}}=\frac{1}{n}$

where $\sigma_{a}$ stands for alternating stress, $\mathrm{S}_{e}$ stands for endurance limit, $\sigma_{m}$ stands for mean stress and $\mathrm{S}_{u t}$ for ultimate tensile stress. Here

$\sigma_{a}=\frac{\sigma_{m a k s}-\sigma_{\min }}{2}$

In fully reversed fatigue loading $\sigma_{\text {maks }}=386.9 \mathrm{MPa}$ and $\sigma_{\text {mas }}=386.9 \mathrm{MPa}$, $\mathrm{S}_{e}=420 \mathrm{MPa}, \sigma_{m}=0 \mathrm{MPa}$ and $\mathrm{S}_{u t}=700 \mathrm{MPa}$. Under these effects the safety factor is found as 1.09. For endurance limit of Ck 45 specimen Sollich et al. [9] could be checked.

For material St 52the highest stress value is $300.9 \mathrm{Mpa}$ and the material has $290 \mathrm{Mpa}$ of endurance limit with 540 Mpa of ultimate tensile strength.

With the same Goodman criteria the safety factor for St 52 is found as 0.35 . The results indicate finite fatigue life of material St 52. On S-N diagram the life of St 52 is found to be 561000 cycles. For St 52 S-N graph Wohlfahrt et al. [10] could be checked out. 561000 cycle stands for 102.5 years considering a fully reversed cycle of 15 per day.

As a simple design criteria stress raising factors should be decreased and a good lubrication of rotating parts should be provided. For some simple design rules on rotating parts apply to Xu et al.[11] and also Fonte et al. [12] should be checked out as a starting reference guide.

\section{NATURAL FREQUENCY ANALYSIS UNDER FORCED CONDITIONS}

The critical speeds and the natural frequencies of shafts exhibit another complex problem. Ganesan [13] has dealt with this problem as considering shafts operating close to critical speeds, here the stability and resonance of shafts were considered. Also $\mathrm{Ng}$ et al. [14] dealed a very close example to shafts - a cylindrical shell - to find the critical speeds of shells. For a simple overview the natural frequency of propeller shafts under $2940 \mathrm{Nm}$ torque value is found. The first six natural frequencies of shafts have been found and the remaining natural frequencies have been neglected since those frequencies are well beyond operating conditions. The results have been tabulated in Table 2.

Especially natural frequencies of mode- 1 and mode-2 are worth attention. These values stand for nearly $1500 \mathrm{rpm}$ which is within the operating rpm for the engine. In this case there might be intersection of engine operating frequency and forced shaft frequencies. To overcome this problem shock absorbers and damping materials are used within the vehicle. This way the risk of resonance is terminated. 


\section{CONCLUSIONS}

An overall analysis of a propeller shaft of a selected vehicle has been carried out in this study. All results are either tabulated or shown on graphs. The results indicate that :

- With increasing torque values Von Mises stress levels increase

- With increasing axis angle stress values increase even if applied torque value is kept constant. In this case the application of simple shear stress formulations is not acceptable.

- Selected propeller shafts show no yielding under these operating conditions. However in real life conditions a careful experimental and analytical procedure must be carried out and the usage of these type of shafts should be verified.

- In fatigue calculations material S-N graphs should be modified to give more realistic results. In this paper although $\mathrm{Ck} 45$ material shows infinite life it must be modified to fit real life conditions.

- St 52 shows finite life under these operating conditions. The possible reason should be its low endurance limit.

- The results in free vibration of shafts give nearly similar natural frequencies. This might be due to the superiority of shape of shafts as stiffness matrix over force matrix. The first two natural frequencies coincide with operating range but cause no problem since damping is also applied.

\section{REFERENCES}

[1] Farfan, S., Gonzalez, C.R., Hernandez, T. C. and Mesmacque, G., "High cycle fatigue, low cycle fatigue and failure modes of carburized steel", International J. Of Fatigue, No.26, pp 673-678, (2004)

[2] Mcclaflin, D. and Fatemi, A., "Torsional deformation and fatigue of hardened steel including mean stress and stress gradient effects", International Journal of Fatigue, No.26, pp 773-784, (2004)

[3] Bhaumik, S.K., Rangaraju, R., Paramesvera, M.A., Venkatasmawy, M.A., Bhaskaran, T.A. and Krishnan, R.V., "Fatigue failure of a hollow power transmission shaft", Engineering Failure Analysis, No.9, pp 457-467, (2002),

[4] Bayrakceken, H., "Failure analysis of an automobile differential pinion shaft", Engineering Failure Analysis, No.13, pp 1422-1428, (2006)

[5] Sonsino, C. M., Kueppers, M., Eibl, M. And Zhang G., "Fatigue strength of laser beam welded thin steel structures under multiaxial loading", International Journal of Fatigue, No.28, pp 657-662, (2006)

[6] Bertini, L., Fontanari, V., Straffelini, G., "Influence of post weld treatments on the fatigue behaviour of Al alloy welded joints", Int. J. Fatigue, No.20, pp 749-755, (1998),

[7] Jen.Y.M., Yip, M.C., Wei, C.L. and Shu,G.C., "Prediction of low cycle fatigue life of sleeve-pin-shaft connections under axial and torsional cyclic loading", International Journal of Fatigue, No.29 ,pp 796-809, (2007)

[8] Yoda, N.A. and Takase,Y., "Stress concentration formula useful for all notch shape in a round bar(comparison between torsion, tension and bending)", International Journal of Fatigue, No.28 (2006), pp 151-163 
[9] Sollich, A. and Wohlfahrt, H., "Optimization of the fatigue strength of heat treated steels as a consequence of an optimum state of the surface and of subsurface layers after shot peening", Welding Institute, Technical University of Braunschweig, Germany

[10] Wohlfahrt,H., Pagel, T. N. and Zinn, W., "Optimization of the fatigue behaviour of welded joints by means of shot peening- a comparison of results on steel and aluminium joints", Welding Institute, Technical University of Braunschweig, Germany, Institute of materials technology, University of Kassel, Germany

[11] $\mathrm{Xu} X ., \mathrm{Yu}, \mathrm{Z}$. And Ding, H., "Failure analysis of a diesel engine gear-shaft", Engineering Failure Analysis, No.13, pp 1351-1357, (2006)

[12] Fonte, M., Reis, L., Romeiro, F., Li B. and Freitas, M., "The effect of steady torsion on fatigue crack growth in shafts", International Journal of Fatigue, No.28, pp 609-617, (2006),

[13] Ganesan, R., "Effects of bearing and shaft asymmetries on the instability of rotors operating at near critical speeds", Mechanism and Machine Theory, No.35, pp 737-752, (2000)

[14] Ng, T.Y. and Lam, K.Y., "Vibration and critical speed of a rotating cylindrical shell subjected to axial loading", Applied Acoustics,No.56, pp 273-282, (1999)

\section{Tables}

Table-1. Stress Values with Different Gear Ratios

\begin{tabular}{c|c|c} 
Gear No. & Von-Mises Stress (MPa) & Safety Factor \\
\hline 1 & 386,9 & 1,27 \\
\hline 2 & 219,9 & 3,23 \\
\hline 3 & 139,85 & 5,59 \\
\hline 4 & 87,6 & 7,61 \\
\hline 5 & 64,4 & 9,76 \\
\hline 6 & 50,2 & 1,39
\end{tabular}

Table-2. Natural frequency Values Under 2940 Nm Torque Applied

\begin{tabular}{c|c|c|c} 
Mode & Frequency & Mode & Frequency \\
\hline $\mathbf{1}$ & $24,5834 \mathrm{~Hz}$ & $\mathbf{4}$ & $169,34 \mathrm{~Hz}$ \\
\hline $\mathbf{2}$ & $24,5995 \mathrm{~Hz}$ & $\mathbf{5}$ & $177,903 \mathrm{~Hz}$ \\
\hline $\mathbf{3}$ & $166,395 \mathrm{~Hz}$ & $\mathbf{6}$ & $251,14 \mathrm{~Hz}$
\end{tabular}




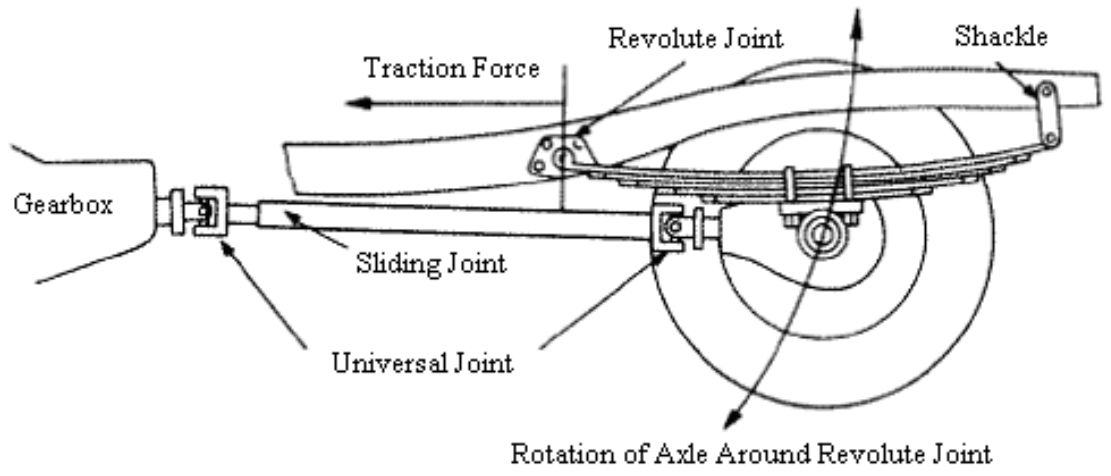

Fig. 1. Explanatory Sketch of Axle Movement Due to Revolute Joint and Road Characteristics

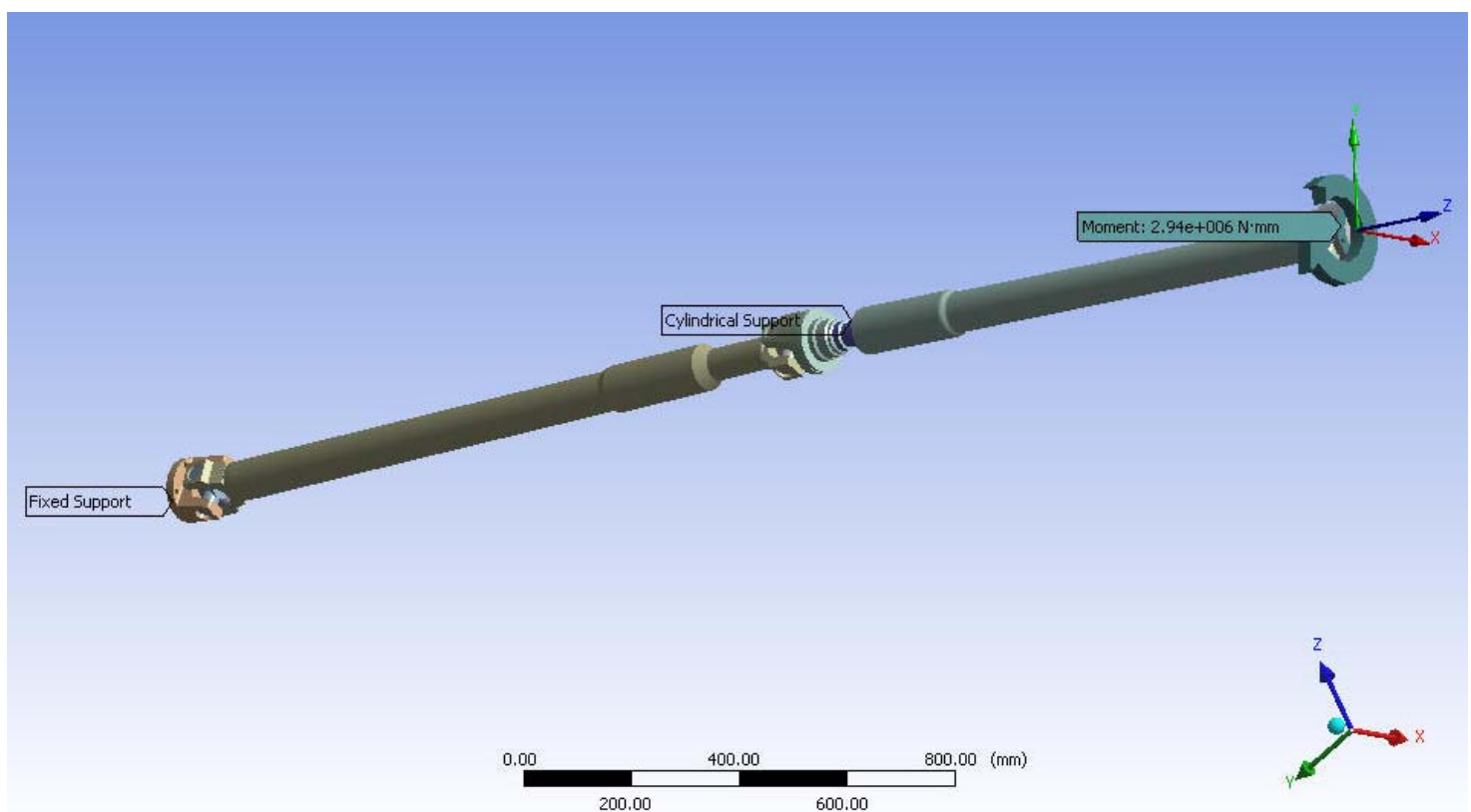

2. 3D Model of Shafts with Constraints Applied

Fig. 


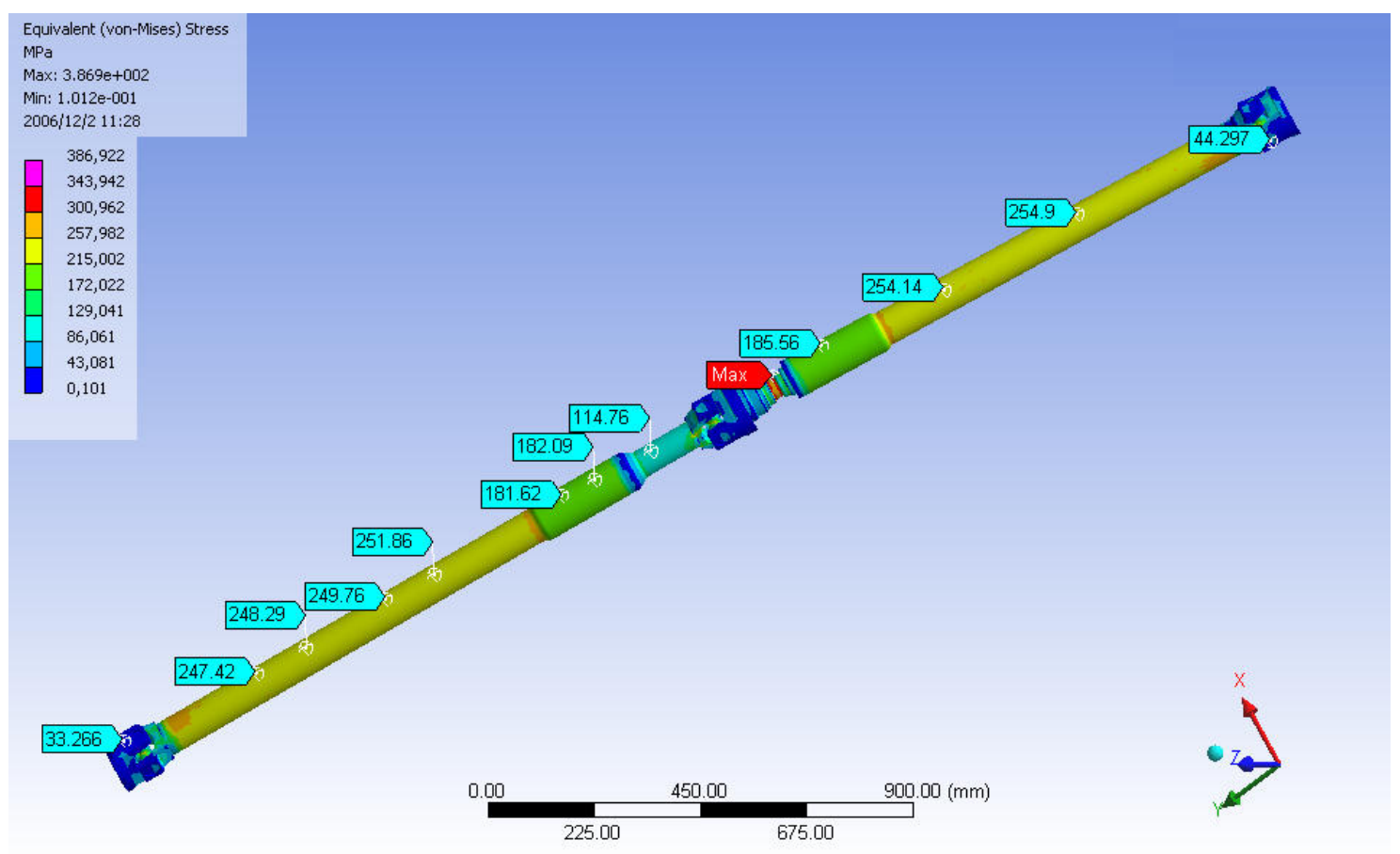

Fig. 3. Sample Analysis Results Under 2940 Nm Torque

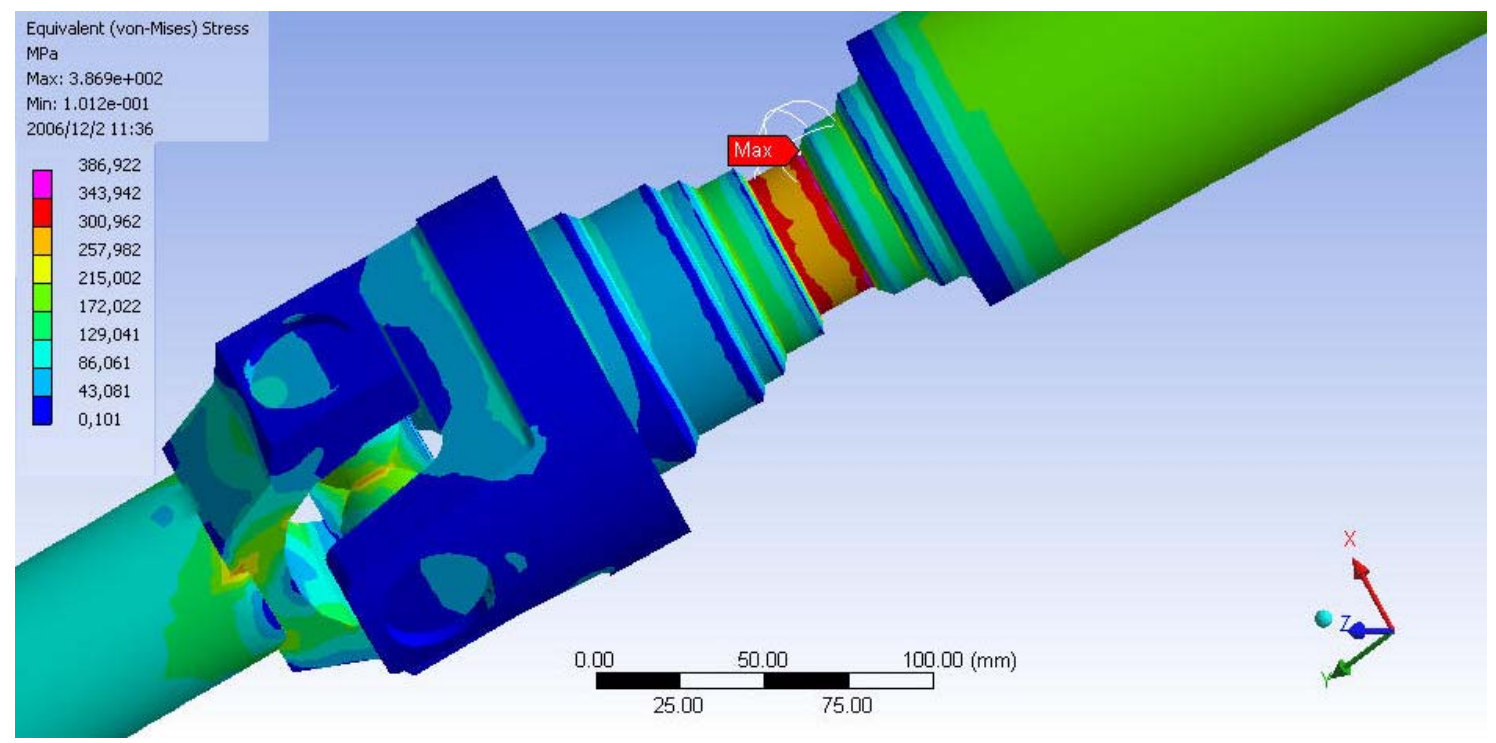

Fig. 4. A Close View of Critical Section 


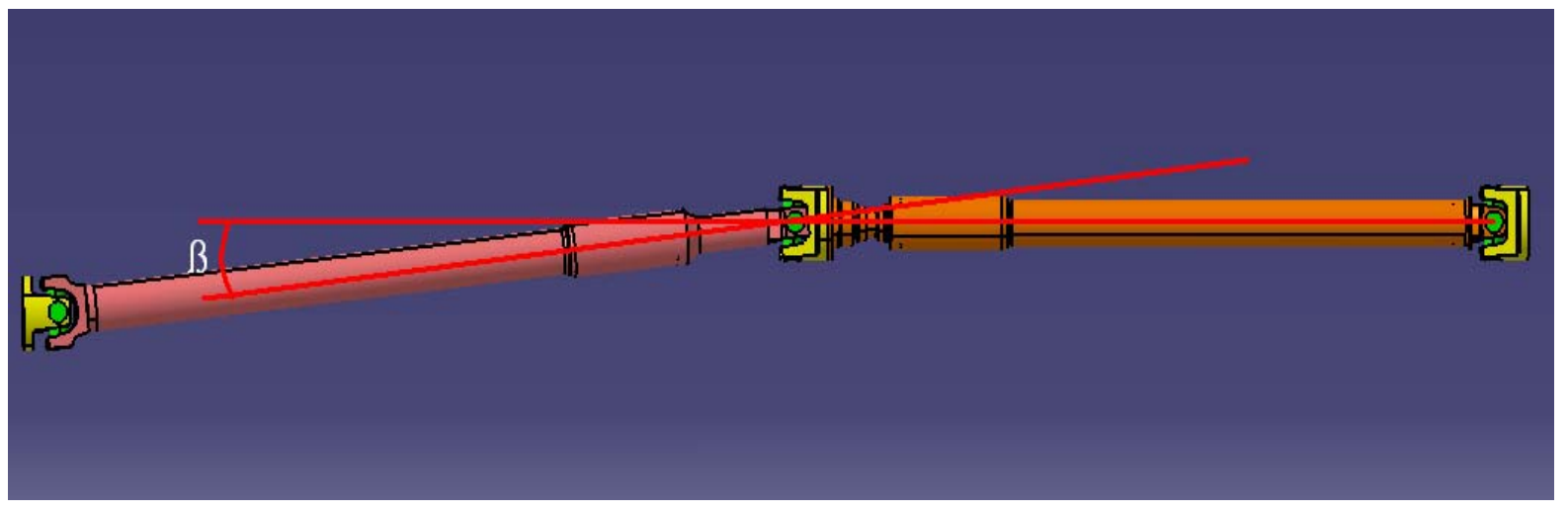

Fig. 5. Axis Angle Variation

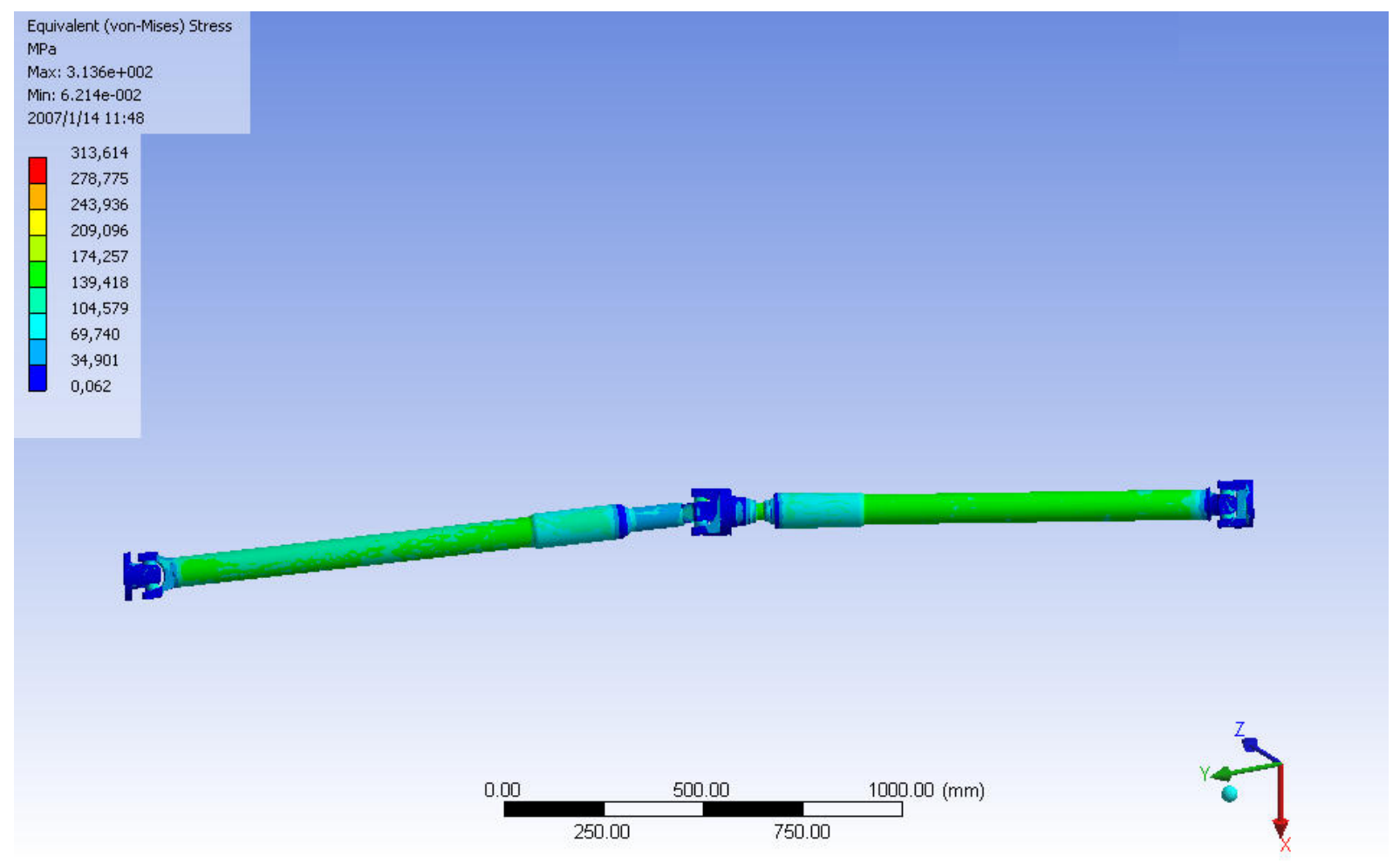

Fig. 6. Variable Axis Angle Stress Analysis $\left(T=1671 \mathrm{Nm}, \beta=6^{\circ}\right)$ 


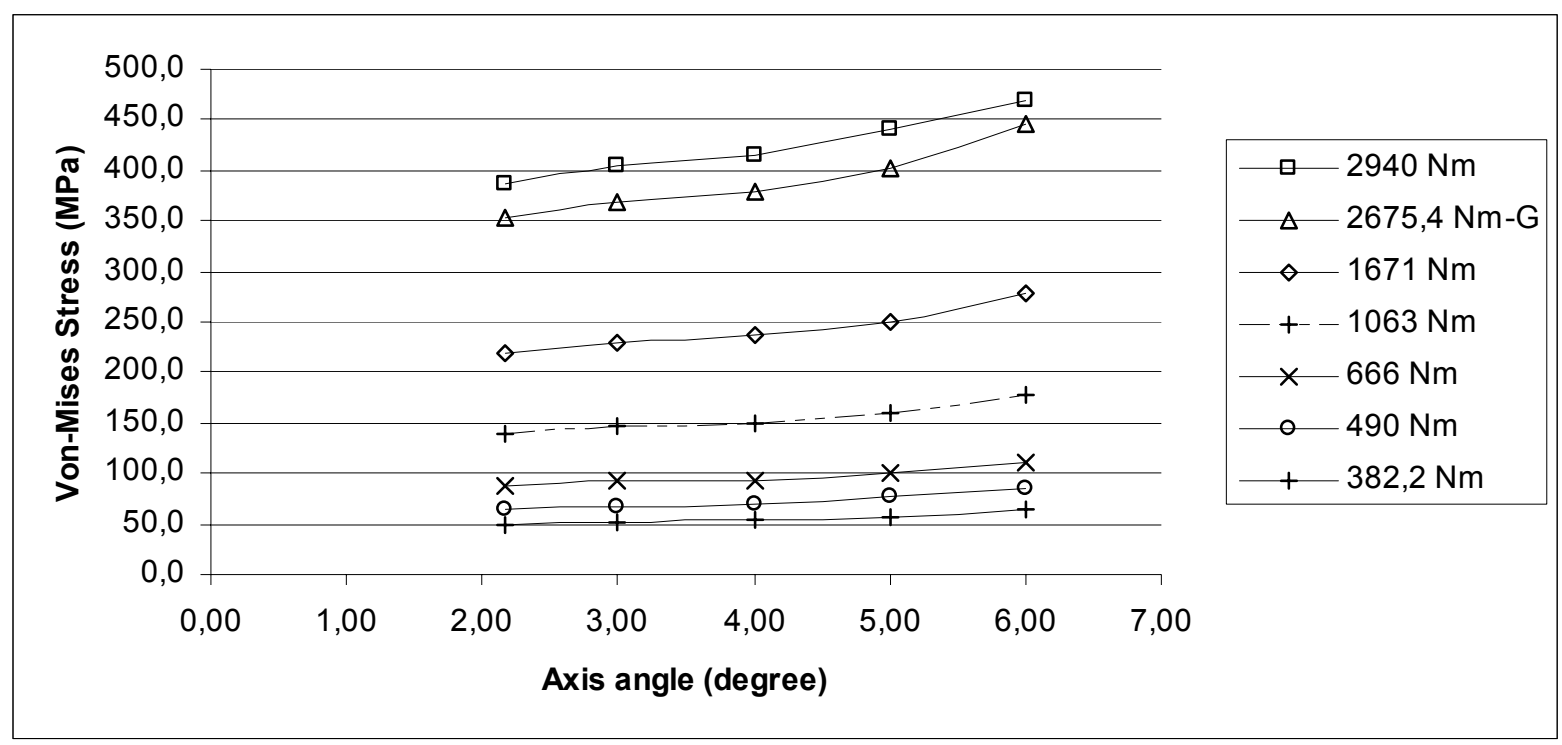

Fig. 7. Total Graph of Variable Axis Angle Stress Analysis 